\title{
The Preliminary Design of Data Acquisition and Control System Simulation for LNG Custody Transfer Based on ISO 8943
}

\author{
${ }^{a}$ Muhammad Arman, ${ }^{b} E d i$ Wahyu Sri Mulyono, a Muhamad Anda Falahuddin, \\ aWirenda Sekar Ayu, ${ }^{\mathrm{c} M o h a m a d ~ F i r d a u s ~ B i n ~ S u k r i ~}$

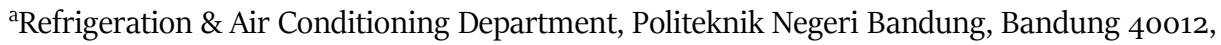 \\ Indonesia \\ ${ }^{\mathrm{b}}$ Chemical Engineering Department, Politeknik Negeri Bandung, Bandung 40012, Indonesia \\ ${ }^{\mathrm{c}}$ Faculty of Mechanical Engineering, Universiti Teknologi Malaysia Melaka, Hang Tuah Jaya 76100 , \\ Durian Tunggal, Melaka, Malaysia
}

Received 11 December 2020; accepted 17 March 2021

\begin{abstract}
Liquefied Natural Gas (LNG) is a complex mixture of low-molecular-weight hydrocarbons with nitrogen as a principal inert impurity. Nowadays, the instrumentation control tools are needed in LNG Commercialization to ensure the LNG is safely transported, while minimizing the energy losses across the network. This research was a preliminary design that used LNG custody transfer control tools referred the ISO 8943:2007 standard. The temperature was measured by thermocouple (Rosemount transmitter 3144 series), while the pressure was measured using pressure transmitter (Rosemount transmitter 3051 series). The simulated signal temperature was done by temperature control box, while the simulated pressure was represented by WIKA pressure calibrator. Data from transmitter was sent to the LabVolt 9063 series that has data acquisition for Software Development Kit (SDK) enabled. Previously, the LabVolt 9063 did not recognized the signal from the transmitter. The SDK software bridged the LabVolt hardware with the LabView software. In the simulated system, temperature alarm will be triggered when the temperature value exceeds $20^{\circ} \mathrm{C}$. For simulated pressure, the alarm will respond if pressure value exceeds 30 psi. From the results of this research, the communication between hardware and software worked properly. The data acquisition system was stable during the data collection stage, processing and displaying. In addition, the alarm indicator for both temperature and pressure was met within the threshold value.
\end{abstract}

\section{INTRODUCTION}

Liquefied Natural Gas, hereinafter referred to as LNG, is natural gas that has been cooled to the point that it condenses to a liquid, which occurs at a temperature of approximately minus $256^{\circ} \mathrm{F}$ (minus $161^{\circ} \mathrm{C}$ ) at atmospheric pressure (Foss, 2007). Chemically, LNG is a complex mixture of low-molecular-weight hydrocarbons with nitrogen as a principal inert impurity. Typically, 
methane is the major component. According to ISO 8943:2007, the minor-component concentrations vary with the source of the raw gas, the liquefaction pre-treatment, the liquefaction process and the storage conditions. Liquefaction reduces the volume of gas by approximately 600 times, thus making it more economical to store natural gas where other forms of storage do not exist, and to transport gas over long distances for which pipelines are too expensive or for which other constraints exist. Liquefaction makes it possible to move natural gas between continents in specially designed ships. Thus, LNG technology makes natural gas available throughout the world (Foss, 2007).

The Commercialization of LNG is based on the level of its energy content. The gas transmission plays a critical role in ensuring these LNGs are safely transported, measured, and recorded before reaching their final destination point. Today, the form of energy transferred based on measurement of the volume in the ship's tanks, measurement of composition from sampling and subsequent calculations of density and gross calorific value from the measured composition. This also requires measurement of displaced gas energy and where applicable energy of boil-off gas consumed by the ship's engine (Kenbar, 2013). Furthermore, in 2017 the "LNG Custody Transfer Handbook" that published by the Groupe International des Importateurs de Gaz Naturel Liquéfié describes fully how LNG energy transferred is determined.

Therefore, if the flow and energy measurements on the inlet and outlet of the transmission network do not match, the lost energy across the network will results in loss of revenue. In such case, the gas chromatographs (GCs) and another instrumentation control tools can be applied to measure the gas transmission. They will provide information on the gas quality and composition. The LNG quality issues are becoming more prominent due to the diversification of supplies, e.g. new LNG terminals, unconventional gas sources and decentralized green fuel injections (hydrogen, substitute natural gas). Furthermore, the growing LNG markets and unconventional gas markets lead to increasing gas quality variations in the grids (Chaczykowski et al, 2017).

In this research, the applications of instrumentation control tools in LNG custody transfer referred to the ISO 8943:2007 standard was conducted. ISO 8943:2007 specifies methods for the continuous and the intermittent sampling of LNG while it is being transferred through a LNG transfer line. In the custody transfer of LNG, it is common practice to determine the quantity transferred on a calorific-content basis. The understanding of the composition of the LNG is required in order to calculate the density and the calorific content of quantities of LNG. Therefore, precise sampling system is a prerequisite for precise analysis (ISO 8943:2007).

\section{METHODS}

In this research, the WIKA Wally Box III model CPH76oo Portable pressure calibrator, Lab Volt Data Acquisition and Control Interface model 9063 enabled with SDK (Software Development Kit), LabView Software 2016, Rosemount Pressure (series 3051) and Temperature (series 3144) transmitter were used. The simulation for LNG condition at the sampling point that stated in the ISO 8943 is used as a standard point of view. Actually, according to ISO 8943:2007, the LNG conditions at the sampling point are as follow: 
- Temperature

- Density

- Flow Rate LNG Sample

- Temperature of atmosphere

- $\quad$ Pressure drop at the end (including valve)
: $113 \mathrm{~K}$

$: 421 \mathrm{~kg} / \mathrm{m}^{3}$

$: 20 \mathrm{~kg} / \mathrm{h}$

: $293 \mathrm{~K}$

$: 50 \mathrm{kPa}$

\section{THE RESULTS AND DISCUSSION}

The first step for the simulation in this research was formulating the parameter that will be used as term of reference i.e., the LNG condition at the sampling point as stated in the ISO 8943:2007. Due to time limitation during this research, the pressure and temperature were the only parameters that had been simulated. In the gas sampling system for the custody transfer of LNG that we want to simulate, the pressure and temperature has to meet the ISO 8943:2007 standard. If the pressure and/or temperature do not meet standard, an alarm is triggered and certain actions should be taken.

The next steps were to set up the hardware and interface into the laptop for monitoring and control the system. At the beginning, the LabVolt 9063 hardware failed to connect properly with the LabView software that already installed in the laptop for the data acquisition processing (see Figure 1). In order to solve this issue, we should enable it assisted by the Software Development Kit (SDK).

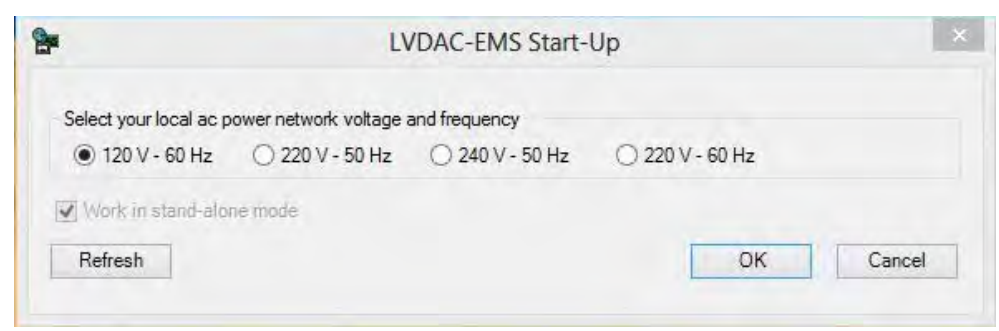

Figure 1. Start-Up Reaction for LabVolt 9063 before Make It Enabled for LabView

After the SDK was enabled for LabVolt 9063, the start-up view is appeared (see Figure 2). The process for SDK enabled is specific and depending on the serial number from the hardware of LabVolt 9063 . 


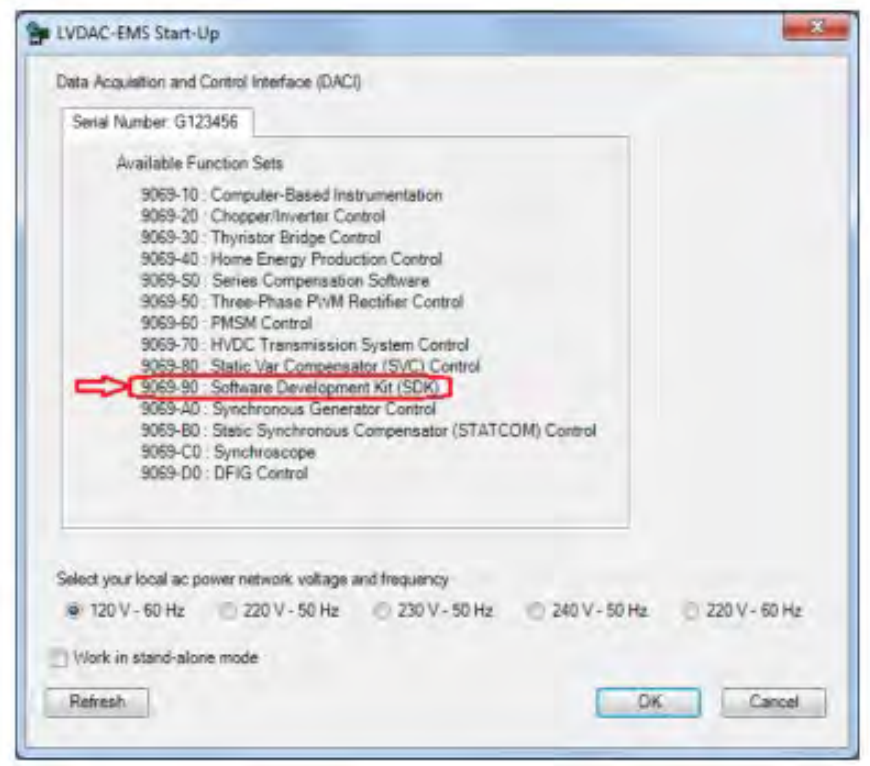

Figure 2. Start-Up Reaction for LabVolt 9063 after Make It Enabled for LabView

The main process flow of the LabView programming is shown in Figure 3. The process of programming in the LabView software consisted of the front panel and the block diagram. The front panel is the human machine interface (HMI) i.e., part as the operators communicate with the equipment and the system, in term of monitoring and control. The block diagram is the main program itself; however, the front panel and the block diagram have interdependency from each other.

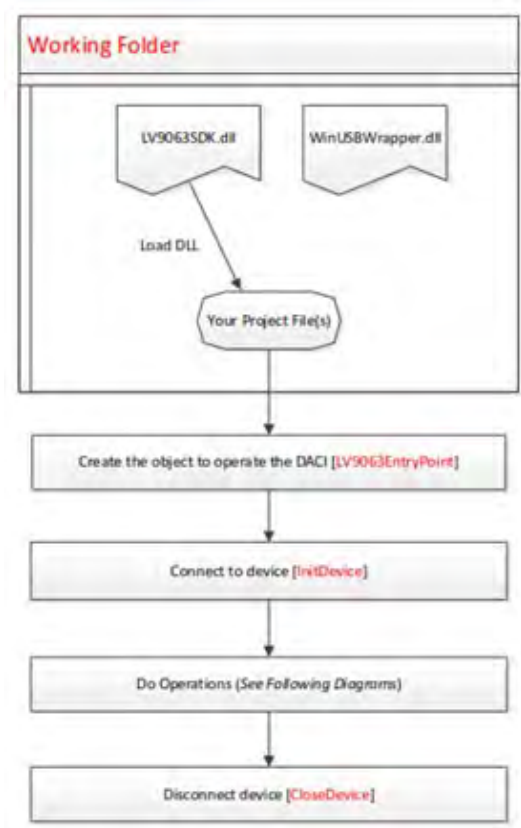

Figure 3. Main Procedure for the LabView Programing 
The block diagram for the data acquisition system consists of three processes: initiation, main program and closing.

1. The initiation

In this part, the LabVolt 9063 has to be initialized so that it can communicate with the LabView programming. The initialization process also check the communication speed, the refresh type and speed; the number of data to be sampled and the sampling rate (see Figure 4). The initiation processes are an important function, where unsuccessful initialization can cause the hardware (LabVolt 9063) and software (LabView) fails to communicate with each other. This failure prevents the next process from running.

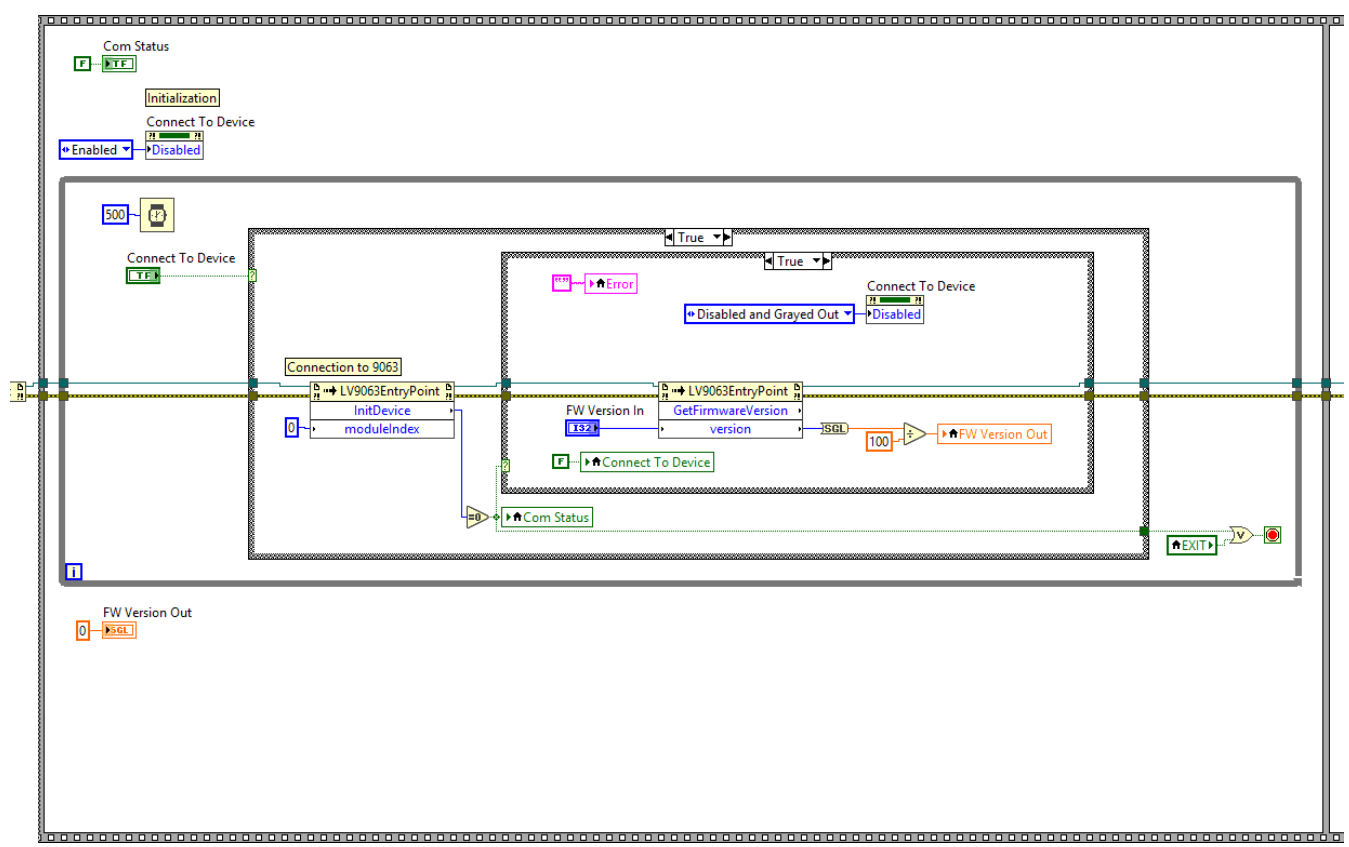

Figure 4. Initiation Process in the Data Acquisition System

2. The Main Program

In this part, the data acquisitions processes are run by choosing the channel and the format data. Error data can also be viewed (see Figure 5). As the data was collected in array, some array managements (such as size and indexing) should be obtained. In the control part, the data was compared with the certain temperature and pressure setup. In this step, if the data exceeded the setup point, then the LED lamp will be triggered. 


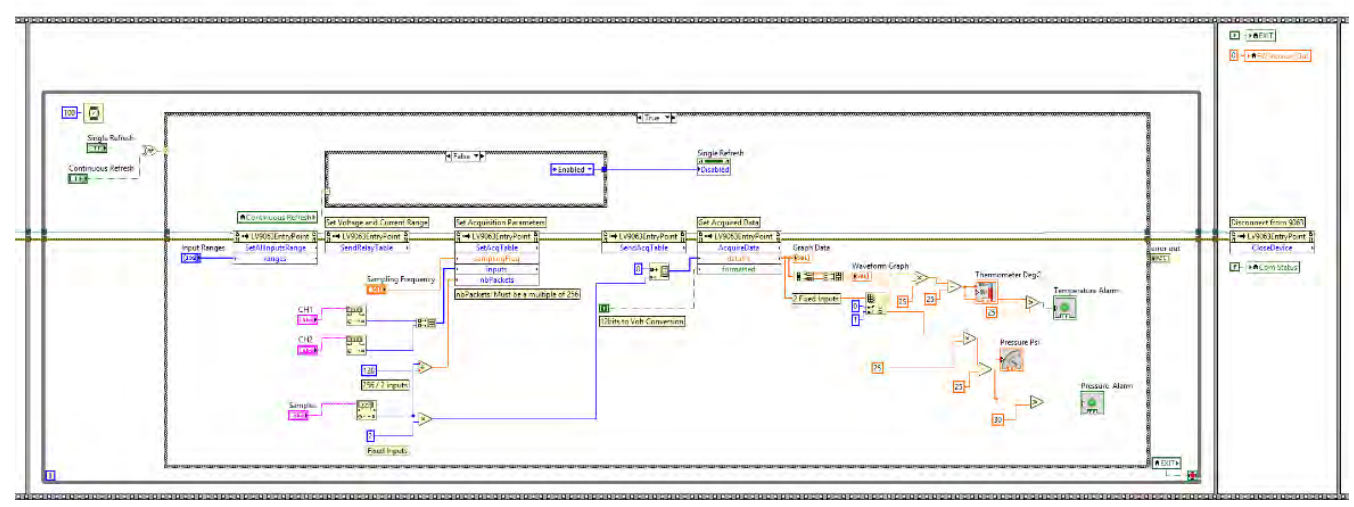

Figure 5. Main Program Process in the Data Acquisition System

\section{Closing}

The last part is a closing process which is the way where the simulation system will be disconnected between the hardware and software (see Figure 6).

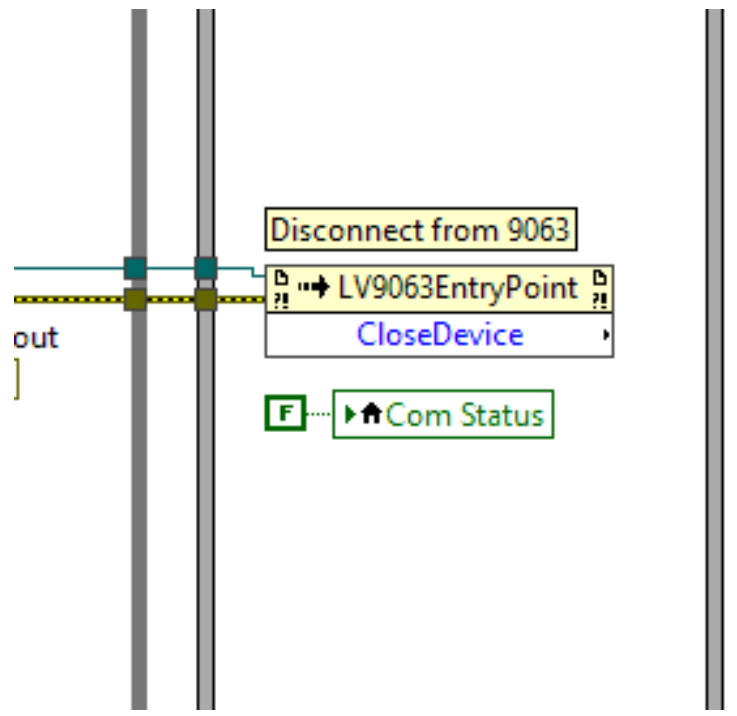

Figure 6. The Closing Process in the Data Acquisition System

Finally, to integrate the sensor and the transmitter, the thermocouple sensor (Rosemount series 3144 transmitter) was used to measure the temperature change, and the Rosemount series 3051 transmitter was utilized to measure the pressure change. The output of this transmitter is 4-20 $\mathrm{mA}$. The transmitter output then converted to voltage by using a precise $250 \mathrm{ohm}$ resistor. The measured value will be read as a scaling number that was run in the main program session. In the simulated system, temperature alarm will be activated when temperature value exceeds $20^{\circ} \mathrm{C}$. For simulated pressure, the alarm responded when pressure value exceeds 30 psi. The wiring system of this simulation connects all the hardware equipment, and it is controlled from the laptop (see Figure 7). The simulation interface is shown in Figure 8. 


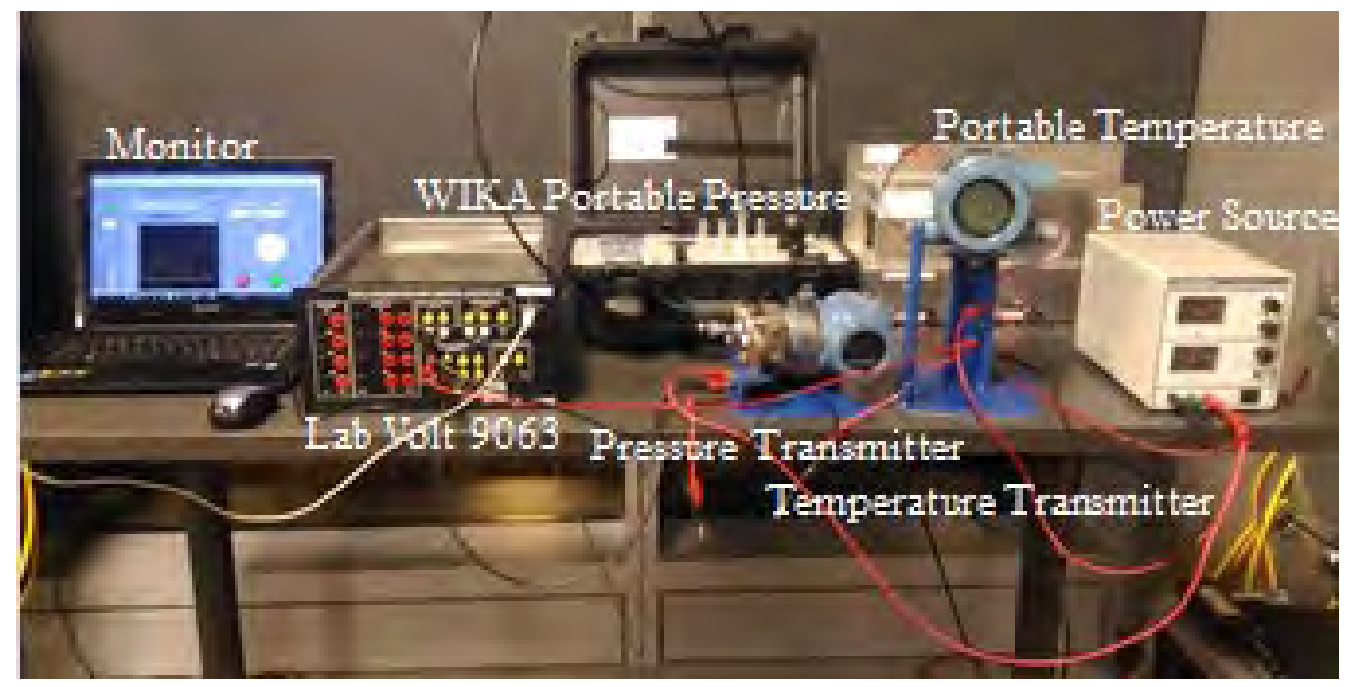

Figure 6. The Wiring System for Hardware and Software Connection

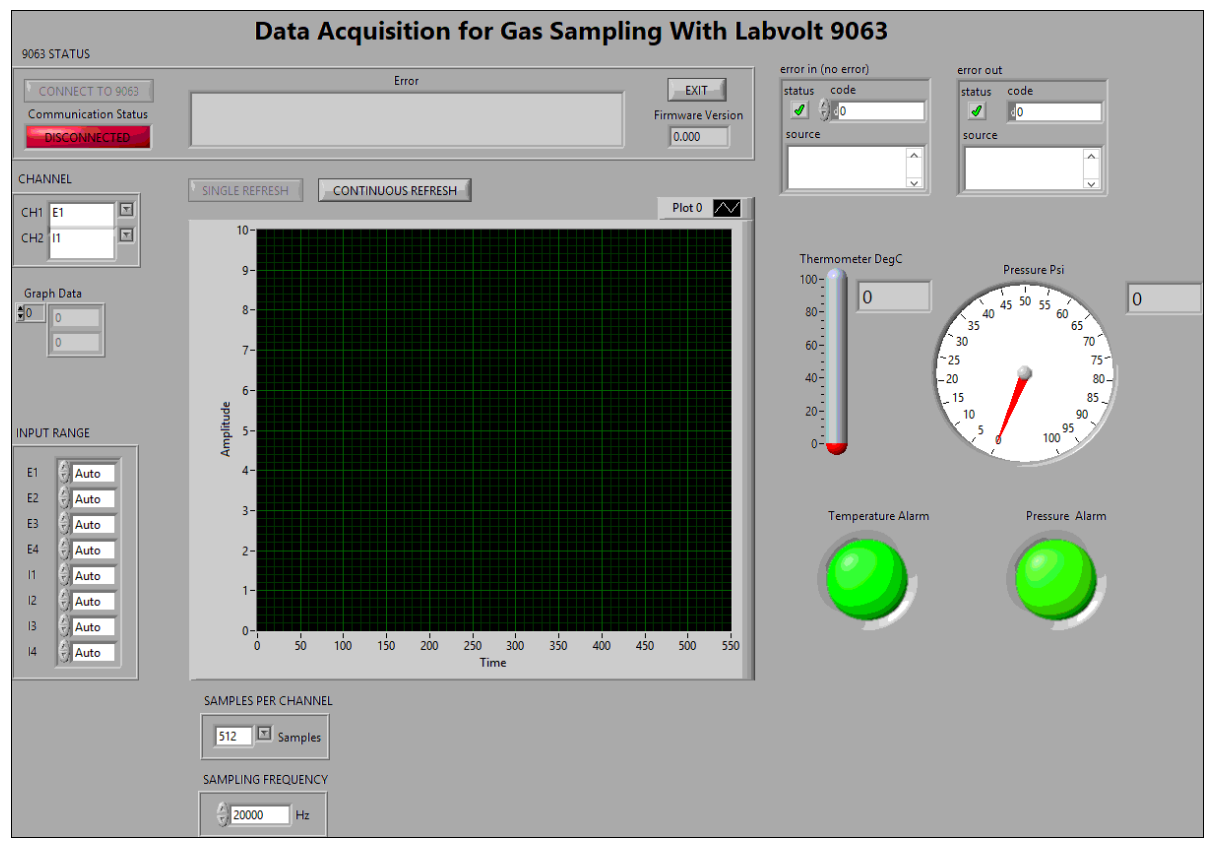

Figure 6. The Front Panel for Data Acquisition System as shown in the Laptop Monitor

\section{CONCLUSION}

The results from this research indicated that:

1. The communication between hardware and software worked properly.

2. The data acquisition system was stable during the data collection, processing and displaying.

3. The alarm indicator for both temperature and pressure was met within the threshold value. 


\section{ACKNOWLEDGEMENT}

This research would not have been possible without the support of the MORTHE Indonesia and MacPhail School of Energy, SAIT Polytechnic, Calgary, Canada.

\section{REFERENCES}

Chaczykowski, M and P. Zarodkiewicz. 2017. Simulation of Natural Gas Quality Distribution for Pipeline Systems, Energy, 134, pp 681-69.

Foss, M.M. 2007. Introduction to LNG, Center for Energy Economics, University of Texas at Austin, Texas.

ISO 8943:2007. Retrieved from https://www.iso.org/obp/ui/\#iso:std:iso:8943:ed-2:v1:en.

Kenbar, A. 2013. Assessment of LNG Sampling Systems and Recommendations, $13^{\text {th }}$ International North Sea Flow Measurement Workshop, 22 - 25 October 2013, Tonsberg, Norway.

G.I.I.G.N.L. (Groupe International des Importateurs de Gaz Naturel Liquéfié). 2017. LNG Custody Transfer Handbook, fifth edition. 